\title{
(Auto) biographical Methodologies to Enhance Learning and Perspectives
}

\author{
Daniel Diego ${ }^{1, *}$ \\ ${ }^{1}$ Benerd School of Education, University of the Pacific, 3601 Pacific Ave, Stockton, \\ California, 95211, United States \\ *Corresponding author: Tel: 1-916-532-4930 E-mail: d_diego@u.pacific.edu
}

Received: August 17, 2013 Accepted: October 26, 2013 Published: November 28, 2013

doi:10.5296/ije.v5i4.4141 URL: http://dx.doi.org/10.5296/ije.v5i4.4141

\begin{abstract}
In order to interpret and learn from complex issues of the past, we must have a deep and well-versed understanding of human history; to do so, many educators and researchers have demonstrated that teaching students to develop multiple perspectives through various modes is one way to achieve this (Ciardiello, 2012). History and identity are documented in narrative and (auto) biographical stories and texts which assist educators in teaching students to develop a stronger awareness of the world they inhabit and the future ahead of them. (Auto) biographical methodologies will illuminate societal developments, cultural changes, and evolution of economic, political, and religious institutions. The aim of this literature review is to understand how educators are using (auto) biographical methodologies to increase awareness and empathy, develop multiple perspectives, and enhance learning of the past, present, and future among students.
\end{abstract}

Keywords: (auto) biographical methodologies; perspectives; narratives; history; empathy 


\section{Introduction}

Autobiographical and biographical methodologies are essential to understanding ourselves, human history, and the progression of human endeavor (Goodson \& Crick, 2009). In order to understand complex issues of human history, society, and beyond, students must be prepared with critical thinking skills to develop, deconstruct, and comprehend multiple perspectives (Ciardiello, 2012; Slattery, 2012). Although what we learn about the past does not provide absolute truth about the present, when we look more closely at perspectives, narratives, and other (auto) biographical materials, we discover that awareness of issues such as class consciousness or any other form of injustice possesses multiple levels and many ways of expressing and revealing itself; be it open, subtle, direct, or distorted (Zinn, 1999). Rather than viewing human history from the outside looking in and as one story told from the dominant perspectives, students and educators must learn to understand human history in a multidimensional, evolving, (auto) biographical way (Slattery, 2012). Utilizing (auto) biographical methodologies will shed light on important aspects of human history and allow students to immerse themselves in the past. From ancient to modern times, from major historical events to the routines common to the context of daily life at the time, perspectives and narratives are fundamental elements for viewing, experiencing, and interpreting human history (Levstik \& Barton, 1996). As students read and experience biographies and narratives of the past, they will come to relate to and understand the motivations, influences, and feelings of the artists, writers, musicians, and common people, not just the dominant powers encountered in their textbooks (Jans-Thomas, 2011). (Auto) biographical methodologies have the potential to enrich many aspects of learning and curriculum, while allowing us to better understand individuals from the past (Fertig, 2008). Based on the literature, it seems reasonable to suggest that if schools are to prepare future generations for the world ahead of them, educators must utilize (auto) biographical methodologies to foster critical, independent thinking among students and teach them not to accept someone else's interpretations without constructing their own.

All too often, history has been perceived and taught as a series of one-dimensional linear events of human nature and conflict as measured by wars, dominant populations, leaders, the founding fathers, and presidential administrations (Slattery, 2008; Zinn, 1999). According to Levstik and Barton (1996), traditional history instruction has also emphasized the influence and power of some individuals over under-represented groups or people. For instance, students will perceive little modeling of alternatives for the future when history is portrayed as examples of men conquering the wilderness, establishing governments, and leading social movements while women are presented as following men to new lands, invisible in government, and silent on most public issues (Levstik \& Barton, 1996). Many researchers and historians understand that multiple perspectives on an event or issue have always existed and that interpretations can be subject to change over time (Bernal, 2002; Delgado, \& Stefancic, 2012; Slattery, 2008) however, researchers have suggested that curriculum taught in schools has often lacked emphasis on the stories and perspectives while remaining focused on the political life of nations and their leaders (Levstik \& Barton, 1996; Slattery, 2012; Zinn, 1999). Far too often, U.S. history instruction has focused on telling the grand narrative story 
of a unified society, while de-emphasizing racial, ethnic, gender, and class distinctions (Levstik \& Barton, 1996; Slattery, 2012; Zinn, 1999). As a result, sub-dominant populations, cultures, and individuals have largely been swept under the rug in the grand narrative of human history (Jans-Thomas, 2011; Slattery, 2012; Zinn, 1999). Historical perspectives and narratives have been used to enlighten students to understand who we are and what we have the potential to become (Levstik \& Barton, 1996); however, we as educators must teach students that the meaning of events cannot be separated from their context and the interpretation of events must be directed toward a synthetic and integrated understanding (Slattery, 2012). In order to address instructional problems that have limited students' understanding of multiple paths and perspectives from the past to the future, (auto) biographical methodologies must be included in the everyday routines of learning (Levstik \& Barton, 1996). The research and literature surrounding these methodologies has demonstrated the need for a well-balanced education to include opportunities for students to participate in meaningful and productive historical inquiry that considers different viewpoints and narrative interpretations while building on their own background and knowledge.

Since history is ongoing and (auto) biographical methodologies tell more than who we are or were at that moment, schools cannot afford a history curriculum mired in trivia and limited to chronological recountings of events (Levstik \& Barton, 1996). Rather, the U.S. education system has demonstrated the need for a vibrant history curriculum that engages students in significant themes and inquiry through the use of (auto) biographical methodologies because history is composed of many stories and narratives, all of which have the potential to appear different due to multiple perspectives (Levstik \& Barton, 1996; Slattery, 2012). Narratives and perspectives regard certain events as important while others see it the opposite, some perspectives see progress where others see decline, and solutions where others see a problem. However different, each story will contain the kind of interpretation that is an inseparable part of historical understanding (Levstik \& Barton, 1996). The purpose of this literature review is to better understand the use of (auto) biographical methodologies to develop and enhance the knowledge and empathy of students. The significance of such a review will contribute to evidence, support, and sources for the practical application of (auto) biographical methodologies in the classrooms, likely to foster deeper and complex multiple perspectives for students to understand and interpret human history and the world they live in.

\section{Inquiry Questions}

1. How are educators using (auto) biographical methodologies to teach disciplines related to History and Social Studies?

2. How do (auto) biographical methodologies influence the understanding of History and Social Studies? 


\section{Literature Review}

When teachers portray human history as an unchangeable sequence of events, facts, and dates, students tend to view the past, present, and future as something fixed, inevitable, and divorced from ordinary life (Levstik \& Barton, 1996); in effect, Zinn (1999) has demonstrated that all too often society has looked to celebrities, leaders, and experts in every field, while separating ourselves and the perspectives of those in the past from the big picture. Comprehending human history through (auto) biographical methodologies will help students to understand how individuals and groups have influenced historical change and worked together to preserve continuity with the past or shape the future (Cain, 2010; Fertig, 2008). In utilizing (auto) biographical methodologies, students gain a deeper empathy for individuals of the past and an enriched understanding of the values and attitudes that motivated predecessors to act as they did (Fertig, 2008; Goodson \& Crick, 2009). Students who do not learn to relate to or see themselves as members of groups that had agency in the past or power in the present, will lack valuable models of the future (Levstik \& Barton, 1996). If history instruction is to allow students to better understand who we are and what we can become, then (auto) biographical methodologies must be included at all levels of education.

\subsection{Narrative Perspectives}

Throughout history, narrative stories and perspectives have been integral elements in understanding the experiences of the individual and the context of society at the time (Ladson-Billings \& Donnor, 2005; Slattery, 2012). According to Goodson (2006), we live in an age where narratives and stories are part of the common currency; however, their scale, scope, and aspirations have greatly morphed to focus on life narratives and small-scale narratives. Furthermore, the link between human history and progress in grand narratives grew exponentially in the mid-nineteenth century but saw its collapse in the twentieth century (Williams, 2005). In this sense, Goodson has explained, the grand narrative has fallen out of fashion since any event can be framed as part of more than one possible story. Furthermore, the history of the twentieth century dissolved the connection between the material and scientific progress and a better moral order with technological advances often having been turned to the business of mass slaughter in global war, genocide, and ethnic cleansing (Goodson, 2006). The fall of grand narratives led to the emergence of smaller narratives, which emphasize individualized and personal life stories while reflecting the dramatic change in the scale of human beliefs and aspiration (Goodson, 2006). By looking at contemporary cultural activity in our highly individualized society, it is clear that the smaller individualized life narrative is emerging as there is not a singular story of history (Levstik \& Barton, 1996; Slattery, 2012). According to Goodson, this has been referred to as the age of narrative -politics, -storytelling, and -identity. When put into historical perspective, however, this era should be seen as the beginning of the age of small narratives with art, culture, and politics increasingly reflective of the shift to highly-individualized or special-interest narratives (Goodson, 2006). Furthermore, the challenge for researchers and educators today is to foster and uncover meaning in individual daily life as expressed in emerging patterns of art, culture, politics, and business with the challenge of studying peoples' lives as part of a wider context of social relations, proprieties and provisions (Goodson, 2006). 
Currently, the rise of the life narrative has come with a range of problems and possibilities for the social scientist and educator and, as Goodson (2006) explained, by examining the wider social context of life narratives, one will begin to appreciate the dilemmas of qualitative work which focuses on personal narratives and life stories. One must be careful, however, because ignorance of social context will deprive oneself and their collaborators of meaning and understanding, since the context in which human lives are lived is central to the core of meaning in those lives (Goodson, 2006). Accordingly, educators and researchers must not discuss or analyze how individuals perceived meaning in their lives and in the world around them while ignoring the content and context of that meaning (Fertig, 2008; Slattery, 2012; Taylor, 2009). Many times a storyteller will neglect the structural context of their lives or interpret such contextual forces from a biased point of view, while acting as if he or she made his or her own history when, in fact, that individual was forced to make the history he or she lived (Goodson, 2006). To help students develop their understanding, teachers must address the narratives of the past while directly building on and relating the knowledge and backgrounds students carry with them (Goodson, 2006).

According to Goodson (2006), in teaching with narratives educators must also examine and acknowledge the problems faced when working with individual life narratives. Goodson's research has demonstrated that the personal life story is an individualizing device and may obscure or ignore collective circumstances and historical movements if devoid of context. The individual life story, as described by Goodson, is itself derived from and highly dependent on a small number of acceptable archetypes available in the wider society. In this respect, the social scripts people employ in telling their life story is a combination of stories and experiences, derived from wider social forces and the personal perceptions of the storyteller (Goodson, 2006; Slattery, 2012). The life story will act as a contextualizing or decontextualizing device and therefore must be culturally and contextually identified in order to pursue understandings (Goodson, 2006; Taylor, 2009). The historical factors associated with time and development must help provide a story of individual action within a theory of context in order to make the transition from life story studies to life histories as educators develop students' biographical understandings of life (Goodson, 2006). Teaching that is focused on helping students understand and make use of past narratives, as well as their own, will contribute to student' understanding of human history and life.

Goodson and Crick (2009) have described narratives as vehicles for learning about life and history which fosters an understanding of multiple perspectives or causes regarding a particular event or context in human history. Furthermore, narratives are told and experienced throughout life and provide a way to understand and connect various life perspectives and experiences to a meaningful understanding of the world around us (Goodson \& Crick 2009). According to Goodson (2006), identity and understanding are embedded in the narratives we tell and experience and can provide reason for action to reconstruct identity. The work of Goodson and Crick has demonstrated that narratives in the classroom relate cultural identity, diversity, and freedom to the lives of all students, as experienced in the stories and relationships of the individual under consideration (Goodson \& Crick, 2009). In order to develop higher level thinking and learning opportunities, examining the narratives and 
perspectives which have shaped or influenced an individual, place, or context under investigation is a crucial step towards a brighter future (Goodson \& Crick, 2009). Although the $21^{\text {st }}$ century has witnessed a shift from grand to small narratives, incorporating various narrative perspectives and stories into education and curriculum to foster broad perspectives and uncover deeper connections and understandings of societies and individuals has been and will continue to be an integral part in preparing future generations to be independent thinkers.

\subsection{1 (Auto) biographical methodologies to enhance learning and perspectives}

Experiencing human history through the study of (auto) biographical methodologies will help students counter the tendency to view the past as inevitable by deconstructing and humanizing the causes of historical change (Fertig, 2008; Slattery, 2012). Misconceptions arise, however, when teachers use (auto) biographical methodologies in isolation of other cultural or analytical tools for constructing historical understanding (Barton \& Levstik, 2004; Wertsch, 1998). When teachers have used (auto) biographical methodologies without accompanying inquiry into the historical context and chronology of people's lives, they have risked instilling the misconception that historical change and continuity resulted solely from the personal intentions and interactions of individuals without recognizing the role societal institutions may have had on shaping historical developments (Barton, 1997). In a study presented by Barton (1997), students often focused on the actions and motivations of individuals while demonstrating little understanding of how changes related to wide social and economic patterns. Furthermore, students in the study also attributed changes in the treatment of women and minorities as the result of changes in individual attitudes, not in combination with a societal process that involved changes in laws and institutions. Recognizing that individuals, groups, and social institutions exercise some degree of influence in shaping history will also help dispel the possible misconception that personal actions are fruitless or futile (Fertig, 2008; Franzenburg, 2010). Simultaneously, (auto) biographical methodologies have enabled young students to identify with individuals of the past and personalize their understanding of history by establishing meaningful affective and intellectual connections with individuals and their circumstances (Cain, 2010; Fertig, 2008). This method of inquiry concerning the thoughts, feelings, and actions of real individuals has contributed to understanding the diversity of perspectives and experiences which have shaped human history for better or worse.

When interpreting historical change and continuity, many students have failed to consider the influence of groups, societal institutions, and socially sanctioned norms or beliefs on how individuals thought and acted at different times in the past (Fertig, 2008; Franzenburg, 2010; Levstik \& Barton, 1996). Improper use of (auto) biographical methodologies has led some students to believe that radical shifts in social structure and development of new technologies took place suddenly and without individuals building on the insights and achievements of others (Fertig, 2008). Although young students have shown susceptibility to misconceptions related to understanding the past, due to a lack of detailed knowledge of contexts and time, there are good reasons for not correcting student misconceptions on the spot because recognizing the multiple causes and effects of a single event is an important goal of historical inquiry that requires time to develop through investigation (Fertig, 2008). Rather than 
correcting misconceptions as they arise, Fertig has suggested that a more effective strategy is to help students interpret narratives and perspectives in ways that lead to an understanding of the historical context and chronology of a specific (auto) biography. Constructing such knowledge in this way will provide students with opportunities to challenge their own misconceptions by asking significant questions about the past, using multiple sources of evidence, and reflecting critically on relationships among individuals, groups, and institutions, all the while collaborating with peers in the process (Fertig, 2008). Student interpretations have sometimes been naïve or incomplete because constructing their own knowledge and challenging misconceptions requires more than students simply regurgitating knowledge that others have produced. It requires students to construct a coherent explanation and interpretation of historical events and issues.

In regard to utilization of (auto) biographical methodologies, Fertig (2008) described several instructional strategies that, with the aid of graphic organizers, will help to cultivate an appreciation and understanding for the importance of historical contexts and chronologies. Fertig has suggested that graphic organizers in concurrence with (auto) biographies will draw students' attention to the ways in which relationships and interactions influenced the values, beliefs, and actions of individuals and promoted historical change. These strategies, according to Fertig, include: (a) comparing and contrasting (auto) biographies with common themes through time; (b) making explicit the relationships between individuals' personal experiences and the institutional arrangements that made up their historical contexts; (c) situating the development of individual beliefs, values, and actions within the context of influential social interactions using group biographies. By using graphic organizers throughout lessons to check for understanding and discuss information that was collected and needed to be added or reviewed, teachers will build on students' knowledge and help make clear connections in history instruction (Fertig, 2008).

When used appropriately, graphic organizers have led students to make connections between an individual's or group's experiences and the laws, dominant economic arrangements, and the socially accepted and sanctioned norms, values, and attitudes of the time (Fertig, 2008). For example, certain graphic organizers allow students to clearly classify different types of social and cultural groups at a particular time and place in history, understand the reasons why individuals sought membership in these groups, and identify various groups' goals in terms of changing or maintaining social relations and economic conditions (Fertig, 2008; Levstik \& Barton, 1996). Teachers have used graphic organizers to show that significant historical change and efforts to maintain continuity resulted from the collective efforts rather than individuals working in isolation (Fertig, 2008). Although students have exhibited difficulty understanding historical change and stability in terms of abstract social structural forces, graphic organizers in combination with (auto) biographical methodologies help foster student understanding (Fertig, 2008). In this sense, students will learn how groups and structures play a part in shaping individuals' thoughts and feelings while giving them a purpose for taking collective action to change history or maintain the status quo in relation to existing social relations and material conditions (Fertig, 2008). Furthermore, by using timelines with graphic organizers in a non-linear way to compare and contrast (auto) 
biographies in history, students will gain greater awareness of historical contexts and changes in material conditions and technology, and the cause-and-effect relationships between the personal experiences and institutional forces (Fertig, 2008). According to Fertig's research, proper use of (auto) biographies to investigate individuals' historical contexts and chronologies will empower students to construct more complete and comprehensive interpretations of historical change and continuity.

Jans-Thomas (2011) has examined the use of children's (auto) biographies to teach African American history, demonstrating how traditional history textbooks in the past have missed the opportunity to teach U.S. history through the artists, writers, and musicians the way European history books have. For this reason, American children have been more conditioned to know the dates of wars, rather than the names of artists and poets, especially African American (Jans-Thomas, 2011; Slattery, 2012). According to Jans-Thomas, using (auto) biographies will counter this precondition and allow students to share and experience the life of an individual through his or her actions, deeds, and achievements. By studying (auto) biographies of those who have spent their lives making a difference through some form of government or social work, students will come to understand that changes often take a lifetime to achieve (Jans-Thomas, 2011). Overall, teaching history with the use of (auto) biographies will help children to see that often many lives intersect and work together to make a difference (Fertig, 2008; Jans-Thomas, 2011).

Aside from (auto) biographical books, examination of other (auto) biographical methodologies, such as spirituals and folk music, will enlighten students. (Auto) biographical art forms and materials such as these assist in teaching students about human history because they maintain the tradition of lyrics and stories being passed down orally by generation, even at times when it was illegal for certain groups and individuals to read or express themselves (Jans-Thomas, 2011). According to Jans-Thomas, professional sports is another example of an arena that has been full of unequal opportunity in the past as experienced by African American athletes who have had to prove themselves in ways white athletes never experienced. For instance, the (auto) biographical experiences of athletes such as Muhammad Ali and Jackie Robinson have acted as examples of people whose notoriety spurred press coverage that often went beyond the rules of the game (Jans-Thomas, 2011). Research has suggested that addressing issues such as these in a genuine way will help students move beyond their own experiences to examine the lives of people whose race, ethnicity, gender, socioeconomic class, or physical ability may be different than their own (Jans-Thomas, 2011).

As a means to explore similar issues and topics, such as Jim Crow laws and other injustices, some educators have used (auto) biographical picture books (Jans-Thomas, 2011). The integration of photographs and (auto) biographies in children's literature allow students to travel in time and experience firsthand accounts of social injustices and historical inequalities by studying images and details sometimes missed by the writer (Jans-Thomas, 2011). The following examples of picture book (auto) biographies have been highlighted by Jans-Thomas (2011) to expand the depth of historical understanding and connections for young students; My name is Pocahontas by Accorsi; A picture book of Anne Frank and A 
picture book of Thurgood Marshall by Adler; The pot that Juan built by Andrews-Goebel; My name is Celia: The life of Celia Cruz by Brown; A boy called Slow by Bruchac; Pocahontas by D'Aulaire; The bus ride that changed history: The story of Rosa Parks by Edwards; Hank Aaron: Brave in every way by Golenbock; The snowy day by Keats; Passage to freedom: The Sugihara story by Mochizuki; Planting the trees of Kenya: The story of Wangari Maathai by Nivola; My diary from here to there/My diario de aqui hasta alla by Perez; Sequoyah: The Cherokee man who gave his people writing by Rumford; El Chino and Tea with milk by Say; Elizabeth leads the way: Elizabeth Cady Stanton and the right to vote by Stone and; Sixteen years in sixteen seconds: The Sammy Lee story by Yoo. In exploring picture book biographies such as these, young students learn to understand concepts and character traits such as fairness by studying the conditions in which under-represented or dominated populations lived and worked and, in effect, develop further inquiry about individual or group happiness, health, and well-being (Jans-Thomas, 2011). Images such as these capture fleeting moments, giving the narratives or (auto) biographies weight and meaning they might not have otherwise had (Jans-Thomas, 2011). Likewise, this imagery will shape how students interpret written texts and perspectives in the past, present, and future.

As ethnic and racial minority groups continue to grow in the U.S. (Vaughn, Bos, \& Schumm, 2007), the need to develop cross-cultural understandings is greater than ever. According to research by Morgan (2009), it is important for young students to develop multiple perspectives through (auto) biographical methodologies. To do so, Morgan has advocated the need for teachers to pay attention not only to how they teach, but also to what they teach and why. The use of well-written picture book (auto) biographies, representing people and groups from diverse backgrounds, will allow teachers to guide students to develop cross-cultural understandings and multiple viewpoints and perspectives at an early age (Morgan, 2009). Morgan's research explained that teaching students to have multiple perspectives at a young age is an important component of early childhood education and has proven likely to reduce problems involving prejudice or discrimination. Conflicts in schools involving racial and ethnic differences have happened due to: courses and textbooks that did not represent students' cultures well, low expectations held by certain teachers toward minority students, and hostile school environments (Bennett, 2007). If students do not learn to understand, empathize with, and respect the perspectives of people who are different than they are, there is no doubt that problems in schools and the wider society will continue to arise (Morgan, 2009). Thus, it has been shown that culturally authentic children's (auto) biographies have the potential to illuminate the various perspectives and frames of references held by individuals and groups while providing an understanding of the society they live in (Jans-Thomas, 2011; Morgan, 2009).

Another important area of biographical injustice has been related to disability history. Nielsen (2012) has explained that (auto) biographies are excellent sources to examine the role and complexities of disability in U.S. history as well as the complexities of U.S. history via disability. When teachers have taken advantage of (auto) biographical methodologies related to disability, students gained new insights about the relationships between individuals with 
disabilities and structural forces with regards to how these individuals both shaped, and were shaped by, the external forces around them (Nielsen, 2012). Through (auto) biographical methodologies and inquiry regarding individuals with disabilities, students begin to understand the historical perspectives and complexities of these individuals in the U.S., while simultaneously realizing that experiences of disability change over time as they are shaped by large structural factors and the bodies of individuals (Nielson, 2012). Furthermore, some of the most important changes in perspective involve the deconstruction and understandings of the way people treat those who they see as different from themselves. The deconstruction of the attitudes towards differences has been and will continue to be responsible for many of human history's most enduring and dramatic struggles and evolution.

According to Nielson (2012), the most common use for (auto) biographies of people with disabilities has been to portray disabled people as inspirational heroes. Sadly, Nielson explained, this method has often led to guilt inducing lessons in an attempt to promote upright behaviors, or to silence students' concerns or grievances about their own lives. Nielson has argued that this has disparaged people with disabilities, reduced them to a series of one dimensional characters, all the while having taught nothing about history. In response, Nielson has advocated the use of (auto) biographical methodologies to teach students that disabled individuals are more than inspirational figures, but part of the complexities of human history is that as students learn that even the definitions of disability change over time (Nielson, 2012). When teachers arm students with an understanding such as this, future generations will be better equipped to empathize with and accept individuals who may be different from themselves.

When considering life narratives and perspectives, solitude has been an aspect that has had little of its story told (Taylor, 2009). According to Taylor (2009), solitude has been a key feature of the human experience and development of a historical understanding of the solitary self is likely to yield valuable insights into the (auto) biographical subject. Solitude has been described by Taylor as one of the great debating points in Western thought stretching back to antiquity, when classical thinkers tended to favor sociality as a virtue as seen in Aristotle's claim of solitude as being fit only for beasts or gods. The solitary self, Taylor argued, adheres to others in an involuntary, and sometimes replenishing or depleting, but always risky relationship. Thus, there has been a need for a biographical perspective that looks inward as well as outward, and to focus on the constitutive elements of human subjectivity as well as its external determinants. However, Taylor cautions, the psychological dimension of (auto) biography has remained problematic as it is possibly the most poorly developed field of modern historical discussion, plagued by 'commonsense' prejudices. All historians use psychology because in a sense it is impossible to write human history without it; however, the psychology that most historians utilize often blends commonplace assumptions about human motivation with bits of pop psychology (Taylor, 2009).

Franzenburgs' (2010) research has shown that socialization goes on throughout life, experiences are often constructed, and that meaning arises mainly from broad, expansive practices. Due to the character of the sources and the need to de- and reconstruct perceptions, memories, and interpretations, (auto) biography must be examined in its social, cultural and 
chronological context (Fertig, 2010). Teachers only concerned with structures, long term processes, and mass phenomena have led students to lose sight of the individuals themselves (Franzenburg, 2010). On the other hand, Franzenburg cautioned that focus on fragmented or inconsistent life stories can also be a weakness when there is a complete lack of theory or methodology. In effect, teachers must understand that in working with an (auto) biographical approach to history, data and facts alone are not sufficient (Franzenburg, 2010). According to Franzenburg, there has been a great need for students to make their own experiences with historical facts, events, and backgrounds so society must preserve the social and cultural heritage of individuals and groups to ensure accessibility and understanding for future generations. Encouraging cross-cultural inquiry challenges traditional interpretations and brings enduring myths into question (Franzenburg, 2010). Cultivating students to be critical, free thinking individuals requires an understanding of the diverse world around and within themselves.

In concordance with research, Franzenburg (2010) concluded that (auto) biographies of individuals and groups provide insights into contexts and interconnections that are relevant to daily life and human history. Together with the focus on everyday written and oral human history, students will learn to integrate facts and emotions into a complete picture of a historical event or fact (Franzenburg, 2010). (Auto) biographical methodologies lead to new insights and points of view that help students to analyze and transfer information into their own life and gain empathy for individuals’ past experiences (Franzenburg, 2010). An (auto) biographical approach integrates data, facts, perspectives, memories, social backgrounds, and personal intentions to understand the motivations, emotions, and actions of individuals and groups in a holistic way (Franzenburg, 2010). Presenting history this way will increase the likelihood that students' schemas will evolve to account for different views overtime, all the while learning from the past.

\section{Conclusion}

Based on the literature and research, the use of (auto) biographical methodologies in the classroom holds great promise for teaching students to construct meaningful knowledge and understanding of important aspects of human history (Goodson \& Crick, 2009). (Auto) biographical methodologies will enable students to develop personalized understandings of history and assist teachers in linking individuals and groups to historical events (Jans-Thomas, 2011). Historical figures, whether famous or previously unknown, are never one-dimensional individuals so educators have the responsibility to enable students to analyze the intersecting nature of identities, hierarchies, and social structures while promoting a celebration of the uniqueness of each individual person, text, event, and culture (Nielsen, 2012). By facilitating (auto) biographical research opportunities, certain educators have motivated students to improve individual and collective historical research and inquiry in the classroom while developing positive character traits (Franzenburg, 2010). Furthermore, (auto) biographical approaches will influence new ways of research and inquiry among students, leading them to not only wonder what happened, but where, why, and with whom did it happen (Franzenburg, 
2010)? These multiple viewpoints or perspectives, as discussed in the literature, will enhance students' views by combining one perspective with others, allowing for more balanced conclusions to be made (Morgan, 2009), as well as teaching young students about inequalities and conflicts involving race, class, ethnicity, gender, and dominated or under-represented individuals (Gollnick \& Chinn, 2009). (Auto) biographical methodologies will foster new insights for students to reflect on the nature and context of human history and understand that such issues and topics are not only complex, but also inseparable (Cain, 2010; Franzenburg, 2010). The mountain of history books under which society stands has leaned so heavily in one direction that narratives, stories and (auto) biographical methodologies must be utilized and reflected upon with more frequency to encourage students to look deeper into, and develop meaningful personalized connections of, complex issues of human history and society (Zinn, 1999). Interpreting the perspectives of individuals or groups from the past is a fundamental aspect of historical inquiry and understanding. By reading and discussing literature, making comparisons to their own experiences, and engaging in inquiry and response activities, students will come to understand the ideas, attitudes, and beliefs that underlay the actions of people in the past and see them as part of a larger social context. (Auto) biographical methodologies are an invaluable means of helping students see human history as meaningful and relevant while they develop attitudes and critical thinking skills necessary for active participation in the world around them.

\section{Discussion}

Throughout human history, narratives and perspectives have been an important part of human understanding and expression. The interpretation and expression of individuals related to issues and contexts of the past is an important aspect of meaningful human understanding. In order to relate to or fathom why individuals acted the way they did, students must be familiar with not only the social and cultural context at the time, but also the values, ideas, attitudes, beliefs, and misconceptions that shaped individuals' thoughts and actions. Currently, from the early primary level to the secondary level and beyond, various educators have discovered and utilized (auto) biographical methodologies to enhance student learning and cultivate deep thinkers as these methodologies have been shown to influence the way students think, perceive, interpret, and express themselves and their understanding. While educators have used many different forms of (auto) biographical methodologies in the classroom, further review and research regarding the integration of arts based (auto) biographical methodologies as an integral part of constructing historical interpretations and knowledge is needed. Art and music are often primary sources that offer unique commentary and perspectives about the context in which they were produced, yet it is unclear the extent to which educators utilize these materials. From the beginning of human history, music and art have been forms of expression that have spoken to both young people and adults, offered contextual commentary, and provided deeper understandings of the recreation, religion, politics, and gender roles that defined and shaped individuals and past civilizations. Art and music have long been central to understanding past and present cultures and populations so it seems only reasonable to suggest that student knowledge and learning about human history and experience would be 
enhanced by the integration of art and music sources into history and social studies curriculum.

\section{References}

Barton, K. (1997). Bossed around by the queen: Elementary students' understanding of individuals and institutions in history. Journal of Curriculum Studies, 12(4), 290-314.

Barton, K., \& Levstik, L. (2004). Teaching history for the common good. Mahwah, NJ: Erlbaum.

Bennett, C. I. (2007). Comprehensive multicultural education: Theory and practice. Upper Saddle River, NJ: Pearson.

Cain, B. (2010). Biography and History. Houndsmilles, Hampshire: Palgrave Macmillan.

Ciardiello, V. (2012). Is Angel Island the Ellis Island of the west? Teaching multiple perspectives- taking in American immigration history. Social Studies, 103(4), 171-176. http://dx.doi.org/10.1080/00377996.2011.606436

Fertig, G. (2008). Using biography to help young learners understand the causes of historical change and continuity. Social Studies, Jul-Aug 2008(99), 147-145. http://dx.doi.org/10.3200/TSSS.99.4.147-154

Franzenburg, G. (2010). Facts as experiences: How to learn and teach history in a biographical way. Problems of education in the $21^{\text {st }}$ century, 25, 21-28.

Gollnick, D. M., \& Chinn, P. C. (2009). Multicultural education in a pluralistic society. Upper Saddle River, NJ: Pearson Prentice Hall.

Goodson, I. (2006). The rise of the life narrative. Teacher Education Quarterly, 33(4), 7-21.

Goodson, I., \& Crick, R.D. (2009). Curriculum as narration: Tales from the children of the colonized. The Curriculum Journal, 20(30), 225-236.

Jans-Thomas, S. (2011). Lives and times: Teaching African American history through biography. Making Connections: Interdisciplinary Approaches to Cultural Diversity, Spring 2011, 65-74.

Ladson-Billings \& Donnor. (2005). Waiting for the call: The moral activists role of critical race theory scholarship. The Sage handbook of qualitative research, 3, 279-302.

Levstik, L., \& Barton, K. (1996). Doing history: Investigating with children in elementary and middle schools. Mahwah, NJ: Lawrence Erlbaum Associates Publishers.

Morgan, H. (2009). Picture book biographies for young children: A way to teach multiple perspectives. Early Childhood Education Journal, 37(3), 219-227. http://dx.doi.org/10.1007/s10643-009-0339-7

Nielsen, K. (2012). Using biography to teach disability history. OAH magazine of history, 
23(3), 41-43. http://dx.doi.org/10.1093/maghis/23.3.41

Slattery, P. (2012). Curriculum development in the postmodern era: Teaching and learning in an age of accountability. New York, NY: Routlage.

Taylor, B. (2009). Separations of soul: Solitude, biography, history. American Historical Review, 114(3), 640-651. http://dx.doi.org/10.1086/ahr.114.3.640

Vaughn, S., Bos, C. S., \& Schumm, J. S. (2007). Teaching students who are exceptional, diverse, and at risk in the general education classroom. New York: Pearson Education.

Wertsch, J. V. (1998). Mind as action. New York: Oxford University Press.

Williams, H. (2005). Extract from Chronology of world history. London, UK: Cassells.

Zinn, H. (1999). A people's history of the United States: 1492 - present. New York, NY: Harper Collins Publishers.

\section{Copyright Disclaimer}

Copyright reserved by the author(s).

This article is an open-access article distributed under the terms and conditions of the Creative Commons Attribution license (http://creativecommons.org/licenses/by/3.0/). 